\title{
Una aproximación a la trayectoria de la literatura jurídica en Colombia en el siglo XIX ${ }^{1}$
}

\author{
Alejandro Londoño TAMAYO \\ CCHS-CSIC Madrid \\ alejandro.londonno@cchs.csic.es
}

Recepción: 2 de marzo de 2011 / Revisión: 15 de marzo de 2011

Aceptación: 19 de mayo de 2011 / Publicación: diciembre de 2011

\begin{abstract}
RESUMEN
Este artículo analiza algunos aspectos de la trayectoria que siguió la literatura jurídica de corte liberalilustrado en el marco de la renovación del pensamiento jurídico que acompañó el inicio del proceso de construcción del estado colombiano. Se pretende identificar cuáles fueron las obras jurídicas extranjeras utilizadas y señalar los espacios temporales en los que ejercieron predominio. También se busca indicar algunos aspectos importantes dentro del proceso de recepción de dichas obras por parte de los juristas nacionales como: las ediciones utilizadas, la circulación que llegaron a tener o los contenidos estudiados. Serán abordadas también algunas de las primeras obras jurídicas que fundaron la ciencia del derecho en el contexto colombiano.
\end{abstract}

Palabras clave: jurisprudencia, bibliotecas, juristas colombianos, literatura jurídica, Colombia, siglo XIX.

\section{An Approach to the Legal Literature in Colombia in the Nineteenth Century}

\begin{abstract}
This article discusses some aspects of the path followed by the enlightened and liberal legal literature produced within the framework of the renovation of juridical thought that accompanied the Colombian state-building process in the nineteenth century. It aims to identify the foreign legal works that were frequently used, as well as the temporal spaces in which they predominated. It also aims to indicate some important aspects regarding how Colombian jurists received these works, such as: the editions used, the circulation of the works and the contents studied. Some of the first legal works, upon which the science of law in Colombia was founded, will also be addressed.
\end{abstract}

Keywords: Jurisprudence, Libraries, Colombian Lawyers, Legal Literature, Colombia, $19^{\text {th }}$ Century.

SUMARIO: 1. Introducción. 2. Bibliotecas y literatura jurídica: representaciones de saberes en uso. 3. Certámenes públicos y cátedras de jurisprudencia. 4. Florentino González y la literatura jurídica inglesa y estadounidense. 5. Conclusiones. 6. Referencias bibliográficas. 7. Fuentes. 8. Anexo.

\section{INTRODUCCIÓN}

La determinación ideológica que le imprimió la literatura jurídica de tinte liberalilustrado a los procesos de formación institucional del Estado republicano y de esta-

${ }^{1}$ Este artículo se inserta en el Proyecto I+D HAR2010-17580. 
blecimiento y práctica del derecho la convierten en un objeto de estudio esencial para la comprensión de la cultura jurídica del siglo XIX colombiano. Esta literatura reúne un conjunto amplio y variado de obras escritas por publicistas europeos y americanos entre finales del siglo XVIII y principios del XIX que la concibieron como un aporte a la renovación de los discursos científico, jurídico y político que debían servir de marco a los nacientes estados liberales. Fueron obras utilizadas generalmente por hombres de leyes -abogados, magistrados, legisladores y gobernantes- con la finalidad de instruirse en la aplicación del derecho, conocer la vanguardia de las teorías y discursos de la época y construir las legislaciones nacionales.

La literatura jurídica en cuestión ha sido un tema poco estudiado por la historiografía colombiana si se compara con otros objetos pertenecientes también al amplio marco de la cultura jurídica decimonónica. A esta carencia se le suma que los estudios que la abordan han adoptado una perspectiva acrítica basada en el concepto de influencia ${ }^{2}$ que ha limitado los problemas que circundan el objeto de estudio y contribuido al enquistamiento de una idea errada de dependencia estatal. Ello ha impedido adentrarse en procesos más complejos como los que plantean la recepción de obras jurídicas y los intereses y disputas que marcaron el acercamiento de las elites hacia éstas. En contrapartida, en este estudio se analizaron algunos aspectos que intervinieron en la recepción de un grupo de obras concebidas en la época como fundadoras de teorías jurídicas como el utilitarismo o el iusnaturalimo moderno. En concreto, se trató de explorar el uso y la circulación que tuvieron dichas obras en el contexto colombiano, de observar la preponderancia de determinados textos y su influjo en la naciente ciencia jurídica nacional y, por último, de señalar los periodos temporales de influencia de las diferentes tradiciones jurídicas. En este sentido, la exploración que se ha realizado implicó necesariamente abordar el proceso de reforma educativa en materia de jurisprudencia que se dio en las universidades y colegios colombianos en la primera mitad del siglo XIX. Esta reforma, que estableció una particular apertura hacia la literatura jurídica extranjera ${ }^{3}$, sirvió en este estudio como un hilo conductor para observar los diferentes aspectos anotados.

La reforma educativa en materia de jurisprudencia fue diseñada para impulsar la transformación jurídica e institucional del Estado de acuerdo con el ideario republicano seguido por la élite dominante, cuyo avance dependía de los logros en diversos campos -la codificación, la separación de la Iglesia del Estado, transformaciones en la administración pública, etc.-, para los que se requería el estudio de nuevos contenidos discursivos. La introducción de nuevas obras jurídicas constituía, en esencia, un paso indispensable para el desmantelamiento del sistema jurídico hispánico y el abandono

\footnotetext{
${ }^{2}$ La utilización regular del concepto de influencia ha sido para describir un proceso de trasvase de unas doctrinas jurídicas de un centro creador a otro receptor que entra a ser pensado como dependiente, inactivo, determinado. Ver un ejemplo de la aplicación de dicha perspectiva en: BARBOSA, 2007, p. 46.

${ }^{3}$ Este proceso fue bastante diferente en contextos como México, donde hubo durante la primera mitad del siglo XIX un particular proceso de adaptación e impresión de obras jurídicas clásicas de autores españoles. Para la segunda mitad de este siglo, según sostiene Jaime del Arenal, las obras españolas perdieron su preeminencia y dieron paso a obras de autores de otros países y a las de juristas mexicanos. Véase: Del Arenal, 1998, p. 33.
} 
de la literatura afín que lo cubría. Era una acción estratégica de cara a la construcción del sistema legalista republicano, en el que la ley sería: "el único instrumento para solucionar los conflictos jurídicos y en el máximo y casi único argumento invocado por unos y otros"4. El Decreto del 3 de octubre de 1826, que postuló un plan orgánico de estudios que cubría todos los niveles y disciplinas escolares, marcó el punto de quiebre en materia de uso de obras jurídicas. Sus disposiciones establecieron los textos que debían servir como manuales para el estudio de las diferentes cátedras que integraban el nuevo plan de estudios de jurisprudencia, para lo que se siguió el criterio de elegir obras modernas según una perspectiva liberal-ilustrada. La reforma dio lugar a la institucionalización de obras pertenecientes a diferentes tradiciones jurídicas, que si bien apoyaban el programa de codificación y de constitucionalismo moderno, también difirieron en presupuestos teóricos de base que posteriormente salieron a relucir en el debate público. Asimismo, el programa permitía a los profesores la elección de otras obras para el apoyo de la cátedra, que debía estar sustentada en el mismo criterio mencionado. Estas disposiciones marcaron una apertura que definió el uso y circulación de un amplio conjunto de obras jurídicas durante todo el siglo XIX, del que bebieron los juristas colombianos encargados de producir las primeras obras de ciencia jurídica; de esta apertura se medirán sus límites y sus posibilidades.

Uno de los procesos que más incidió tanto en el proyecto de reforma de estudios, como en la utilización real de los textos establecidos, fue el desarrollado en el contexto del liberalismo español y especialmente el que tuvo lugar en el marco del Trienio liberal. Los liberales colombianos no reprodujeron lo establecido en los programas educativos españoles, como sí lo hicieron con otros textos legales como fue el código penal $^{6}$; pero sí se sirvieron de las obras de literatura jurídica que fueron traducidas y editadas gracias a la política de las Cortes liberales de publicar obras nuevas para la enseñanza del derecho y a las iniciativas de juristas interesados en la ciencia jurídica de la época ${ }^{7}$. De igual manera, habría que referir que las ediciones españolas realizadas por juristas notables del periodo, impresas a partir de la década de 1820 y otras anteriores, fueron acondicionadas a las particularidades del liberalismo español en

\footnotetext{
${ }^{4}$ Ibidem, p. 32.

${ }^{5}$ Decreto de 3 de octubre sobre el Plan de Estudios, sancionado en cumplimiento del Decreto de 18 de marzo de 1826, sobre que el Ejecutivo forme y mande llevar a efecto el plan de que provisionalmente haya de observase para el establecimiento y arreglo uniforme de las escuelas, colegios y universidades. Véase el decreto en: Riвот y MARch, 1926, pp. 401-451.

${ }^{6}$ El Código penal de la Nueva Granada sancionado en 1837 fue un trasunto del código penal sancionado por las Cortes del Trienio en 1822. Ver: PeÑas, 2006, p. 139; Barbosa, 2007, p. 198. En 1822 Vicente Azuero, Fiscal de la naciente Corte Suprema de Justicia, solicitó al poder ejecutivo ayuda económica para redactar un proyecto de código penal y otro de procedimiento criminal basados en los códigos sancionados por las Cortes constitucionales del trienio liberal. Azuero redactó únicamente el proyecto de código penal el cual determinó toda la estructura del primer Código Penal colombiano que fue sancionado finalmente en 1837. Véase: Proyecto de Código Penal para Colombia tomado con las variaciones necesarias del que presentó a las Cortes españolas por una Comisión en el año de 1821. Bogotá. Imprenta de la República de Colombia. 1823.

7 Martínez neira, 1998, pp. 143-209. Martínez sostiene que la novedad que marca el Trienio liberal en cuanto a la enseñanza del derecho en comparación con los proyectos de gobierno anteriores es el aumento de versiones variadas de obras de derecho natural y de gentes.
} 
materias como la forma de gobierno y la religión católica. El fácil acceso a obras ya traducidas y con las que existía una identificación ideológica hizo que los gobernantes colombianos dieran por hecho el uso de las obras editadas en España, renunciando a la tarea de traducir e imprimir las obras originales; lo que, a corto plazo, hubiera sido una difícil tarea dada la escasez de recursos. Ello no impidió que tal acción fuese modificando paulatinamente.

La identificación de cuál fue el uso y la trayectoria de algunas obras jurídicas durante el siglo XIX en Colombia, la indicación de su peso dentro de la cultura jurídica y la exposición de las corrientes principales que marcaron el inicio de la ciencia jurídica nacional ha supuesto el uso de tres tipos de fuentes y estrategias de trabajo. En primer lugar, se utilizarán los inventarios de bibliotecas pertenecientes a personajes de la vida política nacional, que serán útiles para identificar el tipo de literatura jurídica preferida por éstos y para rastrear algunos cambios de circulación de dicha literatura. En segundo lugar, se rastrearán las obras utilizadas para la enseñanza del derecho en los colegios y universidades, para lo que se recurrirá a los certámenes públicos o exámenes de jurisprudencia; estas fuentes permitirán observar además los contenidos enseñados y exigidos, algunas de las ediciones utilizadas y la regularidad con que los textos jurídicos aparecieron en el contexto educativo. En tercer lugar, se realizarán algunas anotaciones respecto al interés que suscitó la literatura inglesa y norteamericana a mediados del siglo XIX. Para este fin se abordarán las obras del jurista colombiano Florentino González.

\section{BIBLIOTECAS Y LITERATURA JURÍDICA: REPRESENTACIONES DE SABERES EN USO}

Las bibliotecas de actores políticos que participaron en el proceso de construcción del Estado en el siglo XIX reflejan sus intereses por determinada bibliografía jurídica $^{8}$. En este apartado se aplicará un análisis comparado a dos bibliotecas privadas y a un inventario de donación de libros con el fin de identificar qué obras jurídicas poseían los propietarios de los repositorios y de señalar el cambio que se operó en materia de uso y circulación de literatura jurídica entre finales del periodo virreinal y la primera mitad del siglo XIX. Se citarán las obras jurídicas que contenían las bibliotecas con los títulos corregidos y no como fueron anotados por los escribanos. Es de precisar que a la literatura jurídica hallada en estas bibliotecas no tenía acceso la mayoría de la población, sino un sector de la elite política.

\footnotetext{
${ }^{8}$ Dentro de la historiografía colombiana son escasos los estudios sobre bibliotecas. La bibliografía hispanoamericana sobre el tema permite plantear que éstos llegaron a convertirse en una especie de género cuya principal contribución dentro de los estudios históricos radica en su aporte para "la reconstrucción del pensamiento de los propietarios", planteamiento que los autores de estos estudios fundan en la idea de que a través de una biblioteca personal se pueden ver reflejados los intereses y los valores de su poseedor. Este planteamiento, sin embargo, ha sido problematizado, debido a que el criterio de tenencia no garantiza el interés efectivo de un determinado lector en una época pasada por una obra. Ver: Arias, 2005, p. 396. y Márquez, 2002, p. 11. Luque y Vas Mingo, 2006, pp. 128-129.
} 
La primera biblioteca es la de Antonio Nariño9 ${ }^{9}$ que se conoce en su totalidad por el proceso criminal que se le siguió en 1794 por la Real Audiencia de Santa Fé a causa de haber publicado la declaración francesa de Los derechos del hombre y del ciudadano $^{10}$. De los anaqueles de la biblioteca que guardaba en su casa fueron inventariadas obras jurídicas como: Las Institutas de Justiniano, El derecho público de la Europa de Mably, Discurso sobre las penas de Lardizábal, Instituciones del Derecho Civil de Castilla de Asso y Rodríguez, Elementos de derecho público de Olmeda, Compendio del derecho público y común de España de Vicente Vizcaíno, Política española para el más proporcionado remedio de nuestra monarquía de Aguado, Política indiana de Solórzano. También le fueron embargadas en el convento de los monjes Capuchinos de Santa Fé un amplio grupo de obras prohibidas, entre las que se encontraban obras jurídicas como Recueil des Lois constitutives des Etats Unis de l'Amerique de Benjamín Franklin, el Essai sur le Dèspotisme de Mirabeau, L'esprit des Lois de Montesquieu y Legislation universelle de Georges-Louis Schmid ${ }^{11}$. Este recuento de obras permite señalar que Antonio Nariño poseía obras pertenecientes a la tradición jurídica hispánica, obras permitidas y de libre circulación dado que tenían el visto de bueno de la Monarquía; así como obras jurídicas prohibidas en el índice de 1790 como fueron las obras escritas en francés.

Sin embargo, en esta biblioteca no fueron halladas las obras que habitualmente poseían los abogados para el desempeño de sus labores. Este aspecto es importante resaltarlo para no perder de vista cuáles fueron los trabajos de literatura jurídica y los textos legales más habituales de la época. Para ello se trae a colación la donación de un grupo de libros perteneciente al abogado Ignacio Núñez quien inició su carrera a finales del siglo XVIII: La Recopilación de Castilla con los autos acordados, La Recopilación de Indias en pergamino, Las leyes de Toro en pergamino, El Discurso sobre las penas de Lardizábal ${ }^{12}$, Compendio de las partidas, La Curia Filípica, La

\footnotetext{
${ }^{9}$ Antonio Nariño y Álvarez (1765-1823) fue uno de los personajes más destacados del proceso independentista del Virreinato de la Nueva Granada, del que fue ideólogo y dirigente. Ocupó cargos en la administración virreinal como Alcalde de segundo voto en 1789, tesorero de diezmos del arzobispado, regidor y alcalde mayor provincial entre 1791-1793. Durante el proceso independentista fue Secretario del Congreso de las Provincias de la Nueva Granada de 1810, Presidente del Estado de Cundinamarca 1811-1813. A partir de 1821 fue designado por Simón Bolívar como Vicepresidente interino de la recién fundada República de Colombia y senador electo en el año de 1823. Antes de su primera detención por las autoridades en 1794 fue un reconocido vendedor de libros en Santafé y por la misma época logró reunir la biblioteca de corte ilustrado más importante del Virreinato. Véanse: Silva, 2002, pp. 292-297; Molano, 1999; Céspedes del Castillo, 2007, p. 135.

${ }^{10}$ Hernández, 1985, pp. 131-177: Testimonio de Cartas y papeles hallados en estudio de don Antonio Nariño, relativos a la causa que expresa la pieza número; pp. 177-219: Confiscación y embargo de bienes, pp. 219-235: Embargo en el Convento de Capuchinos. El registro realizado a los libros en el inventario de bienes de Nariño tiene errores como omisión de partes de los títulos de las obras y de nombres de los autores; igualmente no fueron indicados datos editoriales como lugar y fecha de publicación. Esto nos llevó a la utilización del estudio de Eduardo Ruíz Martínez que está centrado en identificar cada una de las obras que fueron registradas por los escribanos que participaron de los embargos. Ver: Ruíz, 1990.

${ }^{11}$ Siguiendo la clasificación disciplinar hecha por Ruiz Martínez la biblioteca de Nariño contenía 13 obras de Derecho, 12 de legislación y 22 de política. Ibídem, p. 71.

${ }^{12}$ El Discurso de los delitos y las penas de Lardizábal está presente en los inventarios estudiados.
} 
política de Bobadilla, Instituciones de Derecho Público ${ }^{13}$, Índice General de las Partidas $^{14}$. Una obra que no fue hallada en la biblioteca, pero que interesó especialmente a Nariño y que fue clave dentro de la renovación de estudios impulsada por las reformas universitarias de Carlos III en materia de derecho público fue: Elementos del Derecho Natural y Gentes ${ }^{15}$. Sobre ésta decía el neogranadino en el marco del pleito por el que le fue embargada su biblioteca:

[...] es el libro de la juventud, sus elementos del derecho natural y de gentes, se explican en los colegios por los profesores de derecho público; se sigue la $2^{\circ}$ edición de Madrid, expurgada por Marín y dedicada a un Ministro sabio [...] Cualquiera que lo haya leído verá que deriva los derechos del hombre para consigo mismo, de la igualdad natural que establece por principio. Por lo que hace al derecho natural, todos los hombres son iguales (libro 23 de Reglas jurídicas). A cada paso nos repite Heinnecio que el estado de la naturaleza es el de la igualdad y de la libertad. En los pasajes $5 \mathrm{y}$ 6 del libro $2^{\circ}$ establece este principio de que hace uso en todo el libro. Las reglas generales o principios de nuestros derechos establecidos en la Partida $7^{\mathrm{a}}$, título 34, tiene fuerza de ley; no se le oponen. Dice la primera regla que el Juez debe siempre favorecer la libertad, por que conviene con la naturaleza, que aborrece la servidumbre ${ }^{16}$.

Con este argumento Nariño esperaba demostrar a las autoridades que los textos permitidos por el gobierno para la enseñanza no contenían doctrinas diferentes a las de Los Derecho del Hombre y del Ciudadano. Las obras de Heinnecio relativas al derecho romano fueron establecidas para la enseñanza dentro de los programas republicanos.

La segunda biblioteca analizada es la de Francisco de Paula Santander ${ }^{17}$ de la que quedó constancia en el inventario de bienes relictos realizado a sus pertenencias. Ante la imposibilidad de acceder a su inventario ${ }^{18}$, se acudió al estudio realizado por Eduardo Ruíz Martínez, en el que se identificó y analizó cada uno de los títulos

Esta obra fue publicada por vez primera en 1782 y su falta de reediciones hizo que fuera editada e integrada por Marcos Gutiérrez en el tomo III de su obra Práctica criminal de España.

${ }^{13}$ Pudo tratarse de alguno de los volúmenes de la obra de Ramón Lazaro de Dou: Instituciones del derecho público general de España, publicada en Madrid entre 1800-1803.

${ }^{14}$ Libros donados al colegio de la ciudad de Cali en la provincia de Popayán por su vicerrector el doctor Ignacio Núñez. Gaceta de Colombia, n 132, 25/4/1824.

${ }^{15}$ Se trata de la obra Elementa Juris Naturae et Gentium, traducida y corregida por Joaquín Marín y Mendoza y publicada en Madrid en 1776. De la misma se conocen otras ediciones posteriores como la corregida y reformada por don Mariano Lucas Garrido, impresa en 1837.

${ }^{16}$ Ver: HeRnÁNDEZ, 1985, p. 300.

17 Francisco de Paula Santander (1792-1840) fue el dirigente político más influyente en la construcción del Estado republicano colombiano. Su obra de gobierno la realizó durante sus cargos como Vicepresidente de la República de Colombia entre 1821-1828 y como Presidente de la Nueva Granada entre 1832-2837. Ver: Bushnell, 1984, y MoRENo DE ÁNGEL, 1990.

${ }^{18}$ El documento notarial en el que se recopiló la biblioteca de Santander lo poseyó Rafael Martínez descendiente de éste, posesión que afirmó en uno de sus estudios. El investigador Eduardo Ruíz accedió a dicho documento para realizar su estudio de catalogación de la biblioteca Santander. Ver: Martínez Briceño, 1993, p. 60, y Ruiz, 1993a, p. 104. 
anotados por el escribano que inventarió las pertenencias de Santander ${ }^{19}$. Entre su colección jurídica se encuentran las obras de Jeremy Bentham, su publicista preferido: Draught of a new plan for the organisation of the judicial establishment in France ${ }^{20}$, Fragmento sobre el gobierno, Táctica de las asambleas legislativas ${ }^{21}$ y Tratados de legislación Civil y penal, Panopticon, or the inspection house $e^{22}$; trabajos de de literatura jurídica francesa: El espíritu de las leyes de Montesquieu, Curso de política constitucional de Benjamín Constant, Tratado de economía política de Jean Baptista Say, Leçons de droit de la nature et des gens, de Félice ${ }^{23}$; textos de la literatura jurídica española: Ciencia del gobierno de Antonio del Real, Juzgados militares de España y sus indias de Felix Colon, La teoría de las cortes de Francisco Martínez Marina, Las instituciones de Vinnio castigado por Juan de Sala; o Economía política de Flórez Estrada, Compendio de Antigüedades Romanas de Heinecio; y literatura jurídica producida por autores neogranadinos: La ciencia constitucional de Pinzón, Los elementos del derecho constitucional de Del Real, La ciencia administrativa de Florentino González. A estos libros se agregaban los de otros publicistas americanos como el del venezolano Andrés Bello, Principios de derecho de jentes.

En materia jurídica, la amplia y variada colección de Santander, inventariada en 1840, reflejaba el cambio propuesto por el naciente Estado de Colombia en materia de circulación y uso de literatura jurídica, que se expresó en el Plan de Estudios decretado el 3 de octubre de $1826^{24}$. Este Plan planteaba una apertura en materia jurídica a las obras europeas más afamadas que pudieran contribuir a la ilustración jurídica de los nuevos letrados nacionales y cuyas teorías fueran aptas para apoyar la construc-

\footnotetext{
${ }^{19}$ Ruíz, 1993b, pp. 107-308.

20 Siguiendo el inventario de Ruiz el escribano anotó varios títulos de la siguiente manera: "codificación judicial por Bentham". Teniendo presente que en el caso de uno anotó que estaba en inglés, se puede conjeturar que la obra poseída por Santander fue: Draught of a New Plan for the Organisation of the Judicial Establishment in France: Propose as a Succedaneum to the Draught Presented for the Same Purpose by the Committee of Constitution to the National Assembly, publicada en el año 1789. Ver: Ruíz, 1993b, pp. 107-273.

${ }^{21}$ En el análisis que hace Ruíz Martínez del título anotado por el escribano como "Asamblea legislativa por Bentham", dice que la primera edición en castellano se hizo en 1838; no obstante, se encontró una edición de 1834 por F. C de C, impreso en Madrid en la imprenta de Don Tomás Jordán. El escribano también anota una obra con el título de "Plan de reverencia parlamentaria", que seguramente se trata de la misma obra anotada.

22 El escribano anotó que esta obra se encontraba en 18 cuadernos, edición que no fue posible ubicar. En cambio, se conoce la edición en 3 tomos impresa en Dublín en el año 1791: Panonpticon: or, the Inspection-house. Containing the idea of a New principle of construction applicable to any sort of establishment, in wich persons of any description are to be kept under inspection: And in particular to penitentiary - houses.

${ }^{23}$ El escribano registró el título: "Derecho natural y de gentes por Defeli" y agregó que eran cuatro volúmenes en francés; lo que da lugar a conjeturar de que se trató del Felice, que era como se conocía la obra de Barthélemy de Félice Leçons de droit de la nature et des gens. En la época era frecuente referirse a los libros por el nombre de su autor, esto tanto en España como en América.

24 Se ha elaborado un anexo en el que se precisan las obras establecidas por el decreto de 3 de octubre de 1826, además son presentados los datos bibliográficos de la mayoría de obras de literatura jurídica citadas en el trabajo.
} 
ción del ordenamiento jurídico republicano ${ }^{25}$. Santander fue uno de los promotores de dicha ley lo que explica la posesión de textos cuyo uso defendió. Además, su biblioteca se caracterizó por tener otra serie de documentos jurídicos y legales tales como: memorias parlamentarias, compilaciones de leyes, proyectos de códigos, códigos penales y civiles, catecismos políticos; o reglamentos producidos en diferentes contextos estatales, principalmente los que fueron promulgados en Colombia.

El conjunto de libros de literatura jurídica hallado en la biblioteca de Francisco de Paula Santander, en comparación con el poseído por Antonio Nariño e Ignacio Núñez, permite observar el cambio que se operó en materia de circulación de textos tras el surgimiento del Estado de la Gran Colombia. En la biblioteca de Santander no se hallaron las obras que durante el periodo virreinal fueron esenciales para la enseñanza de jurisprudencia y para las labores de los letrados, como fueron los textos concernientes a la práctica forense y los compendios legislativos españoles; sino que se encuentra de forma más notable una literatura reveladora de nuevas doctrinas que encaminaban la práctica del positivismo jurídico. Santander poseyó algunas de las obras centradas en el derecho natural moderno que habían empezado a ser editadas y traducidas en España a principios del siglo XIX y que se consideraron como rupturistas respecto a obras anteriores centradas en los mismos temas, debido a su mayor complejidad teórica o a la diversidad de temas abordados. La biblioteca de Santander también permite observar de forma clara el interés que empezó a tenerse durante la primera mitad del siglo XIX por la literatura jurídica inglesa y estadounidense.

\section{CERTÁMENES PÚBLICOS Y CÁTEDRAS DE JURISPRUDENCIA}

El Decreto del 3 de octubre de 1826 no sólo estableció los manuales de texto para la enseñanza de las diferentes cátedras del programa de jurisprudencia, sino que también fijó un método de evaluación del progreso de las mismas denominado certamen público. Este estaba articulado en diferentes procedimientos que revelaban el control de la educación por parte del gobierno central. Se iniciaba con la elección de los mejores estudiantes para sostener públicamente una serie de proposiciones; luego, los contenidos a defender debían ser enviados a la Dirección General de Estudios para que los habilitara, siendo excluidas las proposiciones contrarias a la Constitución, a la Iglesia y a la decencia pública; finalmente, se hacía el envío de un informe al gobierno central en el que se describía la realización del acto, el cual debía ser publicado en la gaceta oficial.

${ }^{25}$ El Ministro del Interior José Manuel Restrepo en las memorias que presentó al Congreso de Colombia en el año de 1823 planteaba lo siguiente respecto a las obras que se requerían para los estudios universitarios: "en la reforma y establecimiento de los colegios se tocan las mismas dificultades que en las escuelas primarias: falta de maestros y de libros para las clases. El tiempo solo puede remediar la primera. La segunda podrá superarse si el gobierno es autorizado para hacer venir de Europa o imprimir entre nosotros los cursos más celebres en los diversos ramos de las ciencias y de las artes". LóPEZ, 1990, p. 126. 
Este apartado se centrará en analizar algunos de los informes enviados por colegios y universidades que fueron publicados en la Gaceta de la Gran Colombia y en la Gaceta de la Nueva Granada. El corpus seleccionado entre 1824 y 1840 servirá para establecer cuestiones como: cuáles fueron las obras utilizadas del plan de estudios de 1826 y qué circulación llegaron a tener en las diferentes instituciones educativas del país; cuáles fueron los textos introducidos posteriormente para la enseñanza escritas por autores nacionales; qué ediciones y qué contenidos fueron estudiados. El abordaje de estos elementos contribuirá a verificar una hipótesis: la apertura establecida por la elite política liberal frente a la literatura jurídica extranjera, materializada en la Ley de Educación de 1826, fue concebida, en parte, para no limitar el uso de textos difíciles de adquirir por estudiantes y profesores; esto también se ve reflejado en la libertad que se daba a los profesores para elegir obras de apoyo para sus cátedras. La apertura del abanico de posibilidades de los manuales a utilizar fue una acción ambiciosa que se vio supeditada a las limitaciones existentes sobre el acceso a los mismos, siendo ello lo que terminó por reducir el uso de los textos.

Para la Cátedra de Principios de legislación universal y de legislación civil y penal, fueron establecidas en la ley de 1826 la obra de Jeremy Bentham, Tratados de legislación civil y penal ${ }^{26}$ y los trabajos del Rey de Grenoble ${ }^{27}$. Estos segundos no llegaron a tener ninguna circulación en Colombia, mientras que la obra de Bentham fue considerada como la mejor entre las de los publicistas europeos debido a que su contenido ofrecía a los lectores no sólo principios de la ciencia legislativa, sino instrucciones para iniciar el proceso de codificación al que aspiraba la elite política. Esto le valió una defensa por parte del sector liberal del gobierno que durante todo el siglo XIX estuvo marcada por la discreción y la ambigüedad mantenida por el sector liberal dada la disputa política que generaba la obra.

Los resultados de los certámenes enviados al Ejecutivo muestran que los Tratados empezaron a lograr una circulación y un uso regular en las facultades de Derecho a partir de $1835^{28}$, año en el que fue restablecida tras su temprana proscripción en 1828. Para su restablecimiento el ministro del Interior argumentaba:

[...] la obra circula libremente y por todas partes, sin que pueda ni deba impedirse su introducción y circulación, y si ella ha de ser vista y estudiada por los alumnos de ju-

\footnotetext{
${ }^{26}$ Ver Gaceta de Colombia, $\mathrm{n}^{\mathrm{0}} 215,25-\mathrm{XI}-1825$.

${ }^{27}$ Este autor, del que no se ha hecho ninguna referencia dentro de los estudios de historia jurídica colombiana, no fue desconocido en el contexto de la reforma jurídica y sobre todo de la administración de justicia de la primera mitad del siglo XIX. Ver sus obras en anexo.

${ }^{28}$ Los tratados de legislación civil y penal fueron prohibidos institucionalmente por Simón Bolívar en 1828. La prohibición duró hasta 1835, pero en 1842 volvió a prohibirse durante el gobierno de Alcántara Herrán. A partir de mediados de siglo la obra no vuelve a ser prohibida, pero su uso continúa siendo uno de los puntos de discordia entre liberales y conservadores. Las obras de Bentham podían llegar a tener los siguientes precios: "en 1839 en la tienda de Ulpiano González, en la calle Primera del Comercio de Bogotá, se venden las siguientes obras de Bentham: Tratados de Legislación, 8 tomos $10 \mathrm{ps}$, tratados de los sofismas políticas, 1 tomo $1 \mathrm{ps}$, Táctica de las Asambleas, 1 tomo $1 \mathrm{ps,}$ Organización Judicial, 3 tomos 3 ps, Teoría de las Penas, 4 tomos 4 ps, Defensa de la Usura, 1 tomo 1 ps”. Ver: Gaceta de la Nueva Granada, no 396, 14-IV-1839.
} 
risprudencia, fuera de sus aulas, vale más que lo sea dentro de ellas, bajo la dirección de profesores que cuiden de explicarla, y de que se la repase con fruto ${ }^{29}$.

Los contenidos más defendidos dentro de los certámenes fueron: los principios generales que regían la ciencia de la legislación según la perspectiva utilitarista de su autor, las nociones de legislación civil, penal y de policía, y los principios de codificación $^{30}$. La obra amplió su margen de circulación de Bogotá hacia otros escenarios con la apertura de nuevas cátedras de jurisprudencia que se vieron afectadas también por los condicionamientos establecidos a los profesores frente a las doctrinas perniciosas de Bentham, que eran sus planteamientos críticos hacía el derecho natural, y su concepción utilitarista sobre el placer y la pena que resultaba opuesta a doctrina católica ${ }^{31}$. La edición que circuló con más regularidad fue la de Ramón de Salas, su primer traductor al castellano ${ }^{32}$. Sus interpretaciones a los planteamientos de Bentham, integrados en cada capítulo, llegaron a ser considerados como elementales

\footnotetext{
${ }^{29}$ Resolución por la cual el gobierno insiste en la enseñanza de legislación universal por el texto de Jeremías Bentham. Gaceta de la Nueva Granada, no 212. 18-X-1835.

${ }^{30}$ En el año 1835. Colegio de San Bartolomé, "Octavo acto. Doce cursantes de legislación, bajo la dirección del doctor Florentino González, sostuvieron 19 proposiciones de principios generales de esta ciencia. Nono acto. Diez cursantes de la misma clase expusieron las principales nociones de legislación penal y de la policía". Ver: Gaceta de la Nueva Granada, n 221, 20-X-1835. En el año 1837. En el colegio de Antioquia. " $11^{\circ}$. Los mismos del acto $9^{\circ}$ expusieron en 41 proposiciones los principios generales de la legislación y las máximas que rigen particularmente en legislación civil”. En el Colegio de Chiquinquirá. " 6 . Cuatro cursantes de la clase de legislación explicaron las principales materias de aquella ciencia en la forma siguiente: las proposiciones de legislación universal, 11 relativas al código civil, y 11 acerca del código penal”. Ver: Gaceta de la Nueva Granada, nº 329, 31-XII-1837. En el año 1838, el colegio de Boyacá, " $3^{\circ}$ y $4^{\circ}$ trece cursantes de la legislación expusieron los principios fundamentales de dicha ciencia, así con relación al modo de formar el código civil como el penal". Ver: Gaceta de la Nueva Granada, no 330, 7-I-1838.

${ }^{31}$ Desde el año 1827 el gobierno dispuso que los profesores debían precisar a sus alumnos respecto a Los Tratados: "los errores que algunas personas timoratas juzgan hay en sus doctrinas, y omitiendo la parte o partes que los contengan”. Gaceta de Colombia, n 308, 9-IX-1827. Y en el año 1835 se enfatizó que los profesores debían explicar "las doctrinas y proposiciones de Jeremías Bentham, de modo que ellas no se sobrepongan a las leyes que prescriben la enseñanza de moral y de derecho natural. Por consiguiente, ni podrán enseñarse, ni menos sostenerse en certámenes públicos, principios contrarios a tales disposiciones; sobre lo cual usará de sus facultades naturales la dirección general". Ver: Gaceta de la Nueva Granada, $\mathrm{n}^{\circ}$ 212, 18-X-1835. Esto se vio reflejado en los certámenes como puede observarse a continuación. En el año 1835. Colegio de Vélez. "Duodécimo acto. Siete cursantes de la misma clase expusieron los principios de legislación civil y penal de la obra de Bentham, con excepción de las doctrinas de este autor consideradas como erróneas". Ver: Gaceta de la Nueva Granada, n² 221, 20 $\mathrm{XI} /-835$. En el año 1838. Universidad del Cauca. " $7^{\circ}$ cuatro cursantes de legislación demostraron los principios de esta ciencia contenidos en los cuatro primero tomos de la obra de Bentham, a excepción de las doctrinas contrarias a la religión católica”. Gaceta de la Nueva Granada, n 379, 16-XII-1838.

${ }^{32} \mathrm{La}$ alusión a los tomos que integraban la obra ofrece un indicio sobre la utilización de la edición traducida y anotada por Salas que se publicó en 5 volúmenes en 1820 y en 8 volúmenes en 1823 y 1829 . Ver anexo. En el año de 1838, Colegio de Guanentá " $6^{\circ}$ Nueve cursantes de legislación expusieron los principios de esta ciencia contenidos en los tres primeros tomos de la obra de Bentham". Ver: Gaceta de la Nueva Granada, nº 378, 9- IX-1838.
} 
en la lectura de la obra porque expresaban una doctrina lúcida que para algunos podía ser igual de polémica que la de Bentham ${ }^{33}$.

Para la Cátedra de Derecho Público, Constitución y Ciencia Administrativa se eligió el texto de Benjamin Constant, Cours de politique constitutionnelle. Esta obra tenía para la época un reputado valor científico y había sido publicada de forma temprana una traducción al castellano por el español Marcial Antonio López ${ }^{34}$. A diferencia de Los Tratados de Bentham, ésta no fue prohibida, sino que sirvió para dar argumentos a quienes observaban el principio utilitarista de Bentham como materialista, contrario al derecho natural y a la religión. Su uso y circulación en las facultades estaba pensado para el corto plazo hasta que fueran publicadas obras por juristas colombianos acordes con el sistema republicano.

Los resultados de los certámenes enviados al gobierno indicaban que los principios que más interesaban de la obra fueron: la teoría de la constitución, el orden de los poderes públicos y los diferentes principios inherentes a la idea de Estado republicano: soberanía, libertad, gobierno ${ }^{35}$. La extensión de las cátedras de derecho constitucional hizo aumentar el uso y circulación de la obra, a lo que se sumó que la misma fuese utilizada para estudiar el constitucionalismo colombiano y la ciencia administrativa ${ }^{36}$. Para esta última materia fueron recomendadas obras

${ }^{33}$ Decía Lino de Pombo: "si por una parte los principios generales de legislación universal que establece y desenvuelve el jurisconsulto Bentham, y sobre todo su comentador Salas, pueden dar motivo a alarmas en algunos padres de familia, de otra parte puede más bien influir en ello la falta que acaso haya habido de una explicación minuciosa y detenida de los mismos principios de las respectivas clases, y el recargo de las materias que se enseñen durante el curso, pues todo error que de aquí nazca, y que se propague por una equivocada inteligencia del texto, es realmente perjudicial a la juventud". Gaceta de la Nueva Granada, nº 212, 18-X-1835. La cursiva es mía.

${ }^{34}$ La edición de Marcial López se imprimió en Madrid en 1820 en 3 vols. La comisión de instrucción pública de las Cortes del Trienio Liberal en el año 1820 estableció la obra editada por éste para la enseñanza de derecho político, de la que se valoró que se explicaran adecuadamente: "Las bases y artificio en que estribaban los gobierno monárquicos representativos y las ventajas que producen los estados grandes que las adoptan". Para la edición española López suprimió algunos capítulos del Cours: "uno sobre las cámaras, no admitidas por nuestra constitución y que en mi concepto son diametralmente opuestas al sistema que hemos adoptado, que sustituye por un discurso sobre el Consejo de Estado; otro sobre la libertad religiosa, que considera contrario al artículo 12 del texto gaditano". Ver: Martínez Neira, 1998, p. 162.

${ }^{35}$ En el Año 1824. Actos literarios de la juventud de Bogotá. "En el colegio de San Bartolomé el catedrático de derecho público, doctor José Ignacio de Márquez, presentó al público un cuadro de proposiciones escogidas sobre los elementos del derecho constitucional, que defendió: división y límites de los poderes públicos, la facultad del cuerpo legislativo para arreglar la disciplina exterior de la iglesia y designar el modo que deben ser elegidos sus ministros, sobre la inspección del ejecutivo en las materias en sus propias materias y la intervención judicial para decidir las contiendas que sobre ellas ocurran". Ver: Gaceta de Colombia, no 147, 8-VIII-1824. En el año 1827 en la universidad Central de Bogotá se celebró un acto donde sus alumnos hablaron, basándose en la obra de Constant, sobre la suspensión y violación de las Constituciones, en un año donde se estaba debatiendo la vigencia de la Constitución de Cúcuta de 1821. Ver: Gaceta de Colombia, nº 322, 16-XII-1827.

${ }^{36}$ En el año 1838, Colegio Académico de Antioquia. "Seis Cursantes de derecho constitucional demostraron en 30 proposiciones los principios fundamentales de esta ciencia, explicando la constitución y las leyes eleccionarias de la Nueva Granada". Y en el Colegio Académico de Boyacá. " 3 . Nueve cursantes de derecho constitucional explicaron en 13 proposiciones los fundamentos de 
de difícil adquisición como las de Bonnis y de Poiriez que no fueron utilizadas en el contexto colombiano ${ }^{37}$. A partir de los códigos y compendios de leyes nacionales ya sancionados ${ }^{38}$ y de los capítulos de la obra de Constant referentes a la responsabilidad de los ministros del gobierno y de los funcionarios de bajo rango del Estado, la organización del poder municipal y de otros organismos, los profesores podían cumplir con uno de los objetivos de la cátedra como era dar a conocer las funciones principales de los jefes de la administración y las diferentes obligaciones que ellas les imponían. Sin embargo, las exigencias de este ramo hicieron que los juristas colombianos formaran rápidamente una obra al respecto para Colombia ${ }^{39}$. Con ello la obra de Constant empezó a ser sustituida por las de juristas nativos publicadas a finales de la década de 1830 como el Tratado de ciencia constitucional de Cerbeleón Pinzón y los Elementos de derecho constitucional seguidos de un examen crítico de la constitución neogranadina de Antonio del Real ${ }^{40}$.

Para la cátedra de Historia e Instituciones de Derecho Civil, Romano y derecho patrio, se establecieron en el plan de 1826 las Instituciones de Vinnio y los Elementos del derecho romano de Heinecio. De estas obras los certámenes no permiten ver cuáles fueron los contenidos estudiados, ya que solo fueron registrados los títulos de los libros ${ }^{41}$. Su circulación fue regular si se considera que habían sido introducidas desde finales del siglo XVIII a partir de las reformas carolinas que buscaban una enseñanza del derecho romano más panorámica, sistemática e historicista ${ }^{42}$; éstas fueron de entre las obras sancionadas por la monar-

esta ciencia, exponiendo la constitución de la Nueva Granada y la ley orgánica del régimen político". Ver: Gaceta de la Nueva Granada, no 378, 9-XII-1838.

${ }^{37}$ La obra de Bonnis era Doctrina social o principios universales de las leyes y sus relaciones de pueblo a pueblo deducidas de los derechos del hombre y de los del género humano. Esta fue enviada por su autor a Simón Bolívar en el año 1822. Ver: Gaitán, 2002, p. 96. La obra de Poiriez, en cambio, no ha sido identificada.

38 Véanse algunas de las compilaciones legislativas encargadas por el gobierno colombiano durante la primera mitad del siglo XIX: Cuerpo de Leyes de la República de Colombia, comprende la Constitución y las leyes sancionadas por el primer Congreso general en las sesiones que celebró desde el 6 de mayo hasta el 14 de octubre de 1821; Colección de las leyes dadas por el Congreso Constitucional de la República de Colombia en las sesiones de los años de 1823 y 1824; Recopilación de leyes de la Nueva Granada, comprende toda la legislación nacional vigente hasta el año de 1844; Leyes y decretos expedidos por el Congreso Constitucional de la Nueva Granada en el año de 1848; Código penal de la Nueva Granada de 1837 y el Código de procedimiento criminal de la Nueva Granada de 1848.

${ }^{39}$ Las obras publicadas fueron la de Florentino González Elementos de ciencia administrativa publicada en Bogotá en 2 volúmenes en 1840 y la de Cerbeleón Pinzón Principios sobre administración pública también publicada en Bogotá en un volumen en 1847. Ver Anexo.

${ }^{40}$ La obra de Pinzón fue impresa en Bogotá en 2 volúmenes en 1839 y la de Antonio del Real en Cartagena en un volumen en el mismo año. Ver Anexo.

${ }^{41}$ En el año 1835 en la Universidad del Magdalena y el Istmo: "La clase de derecho civil romano y patrio, compuesta de los cursantes Manuel José Anaya y Rafael Cajar, y presidida por el catedrático, doctor Eusebio María Canaval, defendió 27 títulos de los libros $1^{\circ}, 2^{\circ}$ y $3^{\circ}$ de las instituciones de Justiniano, concordadas con el derecho patrio" Gaceta de la Nueva Granada, n 176, 8-VIII-1835.

42 Martínez Neira, 1998, p. 149. 
quía para los estudios de jurisprudencia las que más vigencia tuvieron durante el periodo republicano. De Las Instituciones fue estudiada la edición que contenía los comentarios de Juan Sala y de los Elementos fue leída la edición traducida y anotada por Antonio $\mathrm{Saco}^{43}$.

De Sala fue también Ilustración del Derecho Real de España, otra obra propuesta para esta cátedra con la finalidad de estudiar el derecho hispánico junto con la obra de Antonio Fernández Prieto Historia del derecho real de España. Estas obras fueron pensadas para el estudio del derecho hispánico que quedaba en vigor dentro de la República mientras era sancionado uno propio. Entre éstas la obra que tuvo una circulación notable como lo reflejan los certámenes fue la de Sala. De esta se mencionan las proposiciones que fueron defendidas, correspondientes a los diferentes títulos contenidos en los libros que integran la obra ${ }^{44}$.

Para la Cátedra de Economía Política se estableció el Tratado de economía política del pensador francés Jean-Baptiste Say. Traducido de forma temprana en la Península ${ }^{45}$ su utilización fue sugerida por el proyecto educativo de Caballero en el año de $1807^{46}$ y llegó a tener una circulación regular durante la década de 1820 , como se observa en los discursos de juristas liberales notables como lo fueron los de Francisco Soto y Ezequiel Rojas. En los certámenes se defendieron diferentes principios desarrollados en la obra como la naturaleza de las riquezas,

${ }^{43}$ Respecto a la obra de Heinecio se halló un anunció que ofrecía varios ejemplares a la venta, en el que destaca el lugar desde donde fueron importados los libros: "Avisamos al público, y con especialidad a los estudiantes de jurisprudencia que en la tienda del señor J. Antonio Vélez se hallan en venta 30 ejemplares de los Elementos del Derecho Romano, por Juan Heinecio, traducidos con propiedad al castellano, con notas por don José Antonio Saco. El editor de este periódico, queriendo hacer un servicio al país, y a instancias del catedrático de derecho civil del colegio de San Bartolomé, encargó a Nueva York 50 ejemplares de esta obra con el objeto de hacerla popular entre nosotros. El plan de estudios previene que al estudiar el derecho civil patrio, se compare con el romano. La utilidad de este estudio para los que se consagran a la jurisprudencia es indispensable. Así pues, harán muy bien los jóvenes principiantes, y aun los viejos abogados, en apresurarse a obtener una obra tan rara en la Nueva Granada, tan instructiva, y de la que han venido tan pocos ejemplares". Gaceta de la Nueva Granada, n 106, 6-IX-1833. Por otro lado, Sala comentaba el interés suscitado en América por sus obras el Vinio castigado y por las Instituciones: "el aplauso con que han sido recibidas en varias partes de la América, de que tenemos noticias ciertas: de suerte que en muy poco tiempo se despacharon enteramente dos ediciones del Vinio castigado, de dos mil ejemplares cada una, y desde el año 1790 se ha despachado una de mil y quinientos de las Instituciones, y solo nos quedan setecientas de otras tres mil, en términos que habremos de hacer tercera edición en el año de 1804". Ver: SALA, 1803, p. IV.

${ }^{44}$ En el año 1833, en el colegio San Bartolomé. "Clases de derecho civil, la de primer año [...] expuso el libro $1^{\circ}$ y 20 títulos del libro $2^{\circ}$ de la ilustración del derecho real de España por don Juan Sala". Ver: Gaceta de La Nueva Granada, no 111, 10-XI-1833. En el año 1835, en el colegio de Guanentá. "Octavo Acto. Cuatro cursantes de la clase de derecho civil expusieron la constitución de la República y las doctrinas contenidas en 39 títulos de la obra de Sala sobre el derecho real de España, aplicados a varias leyes de la república". Ver: Gaceta de la Nueva Granada, n 221 , 20-XI-1835.

${ }^{45}$ La primera traducción de la obra de Say se publicó en Madrid en 3 vols., entre 1804 y 1807. Ver Anexo.

${ }^{46}$ José Antonio Caballero, secretario de Gracia y Justicia de la Monarquía, promovió dos reformas sobre los estudios de derecho una en 1802 y otra en 1807. Ver: Martínez NeirA, 1998, p. 150. 
las operaciones productivas, la naturaleza de los efectos de los cambios de las monedas, la influencia de las instituciones sobre la economía de las naciones, etc. ${ }^{47}$

Para la Cátedra de Derecho Internacional o de Gentes se estableció como manual la obra de Vattel El derecho natural o principios de la ley natural, y como obras de consulta para los profesores las obras de Martens, Burlamaqui y Azuni ${ }^{48}$. En los certámenes los temas estudiados de la obra de Vattel fueron los relativos a la guerra y la paz o las relaciones reciprocas entre los estados. Los contenidos de la obra fueron enseñados en concordancia con los tratados diplomáticos que empezaron a ser establecidos entre la naciente republica y otros $\operatorname{estados}^{49}$. Más temprano que en otras materias, en reemplazo de esta obra, salieron a la luz las producciones de los juristas nacionales, como lo muestra el primer manual de Francisco Javier Yanes y la obra de Andrés Bello ${ }^{50}$.

${ }^{47}$ En el año 1825, En el colegio de San Bartolomé: "Por la tarde Ezequiel Rojas, con su catedrático doctor Francisco Soto, defendió en conclusiones de economía política el primer de la obra de Juan B. Say [...] Desde la conquista hasta ahora no habían resonado en nuestros colegios las voces economía política, valores, capitales productivos e improductivos, productos inmateriales, etc". Gaceta de Colombia, $\mathrm{n}^{\circ}$ 197, 24-VII-1825. Ver también Certámenes literarios en la Universidad del Magdalena e Istmo y Pore, Gaceta de la Nueva Granada, no 176, 8-II-1835; Certámenes públicos en el Colegio del Rosario, Gaceta de la Nueva Granada, ${ }^{\circ}$ 166, 8-XI-1834.

${ }^{48}$ La obra de Vattel, El derecho de gentes, o principios de la ley natural aplicados a la conducta y a los negocios de las naciones y de los soberanos, fue publicada por primera vez en castellano en Madrid en el año 1820 en 4 volúmenes. Sobre las diferentes ediciones de esta obra ver: GAITÁN, 2002, p. 90, nota 61. La obra de Burlamaqui, Elementos de derecho natural, también fue publicada en Madrid en 1820. La obra de Azuni Sistema universal de los principios del derecho marítimo de la Europa, fue traducida por Rafael Rodas y publicada en castellano en Madrid en 1803. La obra de Karl Martens, Manual diplomático, ó compendio de los derechos y funciones de los agentes diplomáticos: seguido de una colección de actas y oficios escogidos para servir de modelo a las personas que se dedican á la carrera diplomática, fue traducida al castellano por Mariano José Sicilia e impresa en parís en el año 1826. Los datos bibliográficos completos de estas obras pueden verse en el anexo.

49 En el año 1827, certámenes de la Universidad central de Bogotá. "Día 22. Los de derecho internacional, que presidió el doctor Ignacio Herrera, hicieron ver lo que era una nación, un gobierno y una constitución, cómo se puede variar ésta, y en qué consiste la independencia de las leyes y del régimen interior de un Estado". Gaceta de Colombia, no 322, 16-XII-1827. En 1825, Certamen de la universidad de Caracas.: "Alejo Fortique, bajo la dirección de su maestro el doctor Andrés Narvarte, ofreció sostener las siguientes proposiciones: 1 . Por naturaleza propende el hombre a su conservación y felicidad. 2. La soberanía reside esencialmente en la nación. El patronato, o el derecho de presentar las piezas eclesiásticas es una prerrogativa de los Estados soberanos". Gaceta de Colombia, n 175 , 20-II-1825.

${ }^{50}$ El rector de la Universidad de Caracas, Felipe F. de Paul, imprimió a coste de la universidad el texto escrito por el profesor Javier Yanes Idea general ó principios elementales del derecho de gentes: extracto de Vattel y otros autores del que envío una copia al Vicepresidente Santander en el año 1825. Ver: Gaceta de Colombia, no 175, 20-II-1825. La primera edición de Principios de derecho de jentes de Andrés Bello se publicó en Santiago de Chile en 1832. 


\section{FLORENTINO GONZÁLEZ Y LA LITERATURA JURÍDICA INGLESA Y ESTADOUNIDENSE}

Las obras jurídicas publicadas por Florentino González ${ }^{51}$ son una fuente para observar el cambio producido en el círculo de juristas y gobernantes colombianos del siglo XIX con respecto a sus intereses por la literatura jurídica extranjera. El establecimiento de un Estado federal que empezó a sentar raíces sólidas a partir de 1858 se fundó, en buena medida, sobre un discurso que señaló la inoperatividad e imperfección de las instituciones jurídicas establecidas -particularmente de la administración de justicia- y que proponía para su arreglo, entre otros aspectos, atender al modelo estadounidense. El cambio de modelo de Estado -de uno centralista que había imperado durante casi medio siglo a otro federalista- impulsó un acercamiento a la literatura jurídica inglesa y estadounidense, por esperarse hallar en ellas explicaciones teóricas y prácticas sobre el funcionamiento de un Estado federal, del poder judicial y de instituciones como el jurado. Sin embargo, dicha literatura no desplazó fuertemente el valor de la literatura jurídica española o francesa.

En este apartado, se atenderá a dos obras de Florentino González no mencionadas por la historiografía jurídica colombiana, quizá por haber sido publicadas en Argentina y no en Colombia, donde aparecieron sus principales obras, en las que se observa además su interés por la literatura jurídica inglesa y estadounidense ${ }^{52}$ : Lecciones de derecho Constitucional y El juicio por jurados breve noticia. De ambas se abordará el juicio por jurados, que resulta ser no solo una de las contribuciones defendidas por el jurista con mayor ahínco para la reforma del sistema de justicia hispanoamericano, sino también uno de los aspectos en los que la literatura jurídica inglesa y estadounidense tuvo mayor impronta sobre el pensamiento colombiano e hispanoamericano.

Florentino González enfatizaba en los escritos mencionados que uno de los mayores defectos del constitucionalismo hispanoamericano radicaba en que no tenía una garantía judicial que pudiera hacer efectiva las declaraciones de libertades y derechos expresadas en la ley. Ello las convertía en vanas palabras que "podían hacer honor a la buena intención del legislador, pero que no hacen ninguno a su ciencia y previsión" ${ }^{3}$. Para garantizar una constitución no bastaba con dividir el ejercicio del

${ }^{51}$ Florentino González (1805-1875) fue uno de los juristas más notables del siglo XIX dada su participación en algunas de las principales reformas de corte liberal, sobre todo en las realizadas a mediados de siglo en materia fiscal, libertad de esclavos, pena de muerte, inmigración de extranjeros, libertad absoluta de imprenta. Durante su vida política en Colombia ocupó diferentes cargos como: profesor de derecho, diputado y ministro, a su vez que fue conocido por su actividad periodística. $\mathrm{Su}$ formación estuvo marcada por sus viajes a Europa. La mayor parte de sus obras fueron publicadas en Colombia. Ver: Torres, 1868, pp. 363-412. Самacho, 1946, pp. 36-42.

${ }^{52}$ En Argentina González vivió el final de su vida, allí ocupó el cargo de profesor de derecho constitucional de la universidad de Buenos Aires y participó en la comisión de establecimiento de la ley de juicio por jurados. Ver: El juicio por jurados, Comunicación presentada por el académico Fernando N. Barrancos y Vedia, en sesión privada de la Academia Nacional de Ciencias Morales y políticas de Argentina el 26 de octubre de 2005. Disponible en: http://www.ancmyp.org.ar/user/files/ Vedia.pdf

${ }^{53}$ GonzÁlez, 1869a, p. III. Texto consultado en The British Library. Signatura: 1607/1252 
poder en varias instancias, sino que había que darle participación a la ciudadanía tanto para ejercer medios de control sobre el gobierno, como para desempeñar funciones que estaban establecidas únicamente para éstos. Asimismo opinaba que tampoco se había ejecutado de forma adecuada el principio de división del poder público; lo que se observaba en la permanente sujeción del poder judicial al Ejecutivo y al legislativo ${ }^{54}$. Ante ello, González proponía dirigir la mirada hacia el funcionamiento del poder judicial en Estados Unidos, y en particular, a la institución del jurado, que a su juicio era la un elemento central de un gobierno popular representativo ${ }^{55}$. Argumentó que este sistema contribuiría a corregir una organización judicial perniciosa como la basada en los principios de la jurisprudencia romana y napoleónica de la Europa continental. Para probarlo, González desarrolló en sus obras dos análisis complementarios: en primer lugar, un análisis de la institución del jurado a partir de obras de jurisconsultos anglosajones, por considerarlas las únicas aptas para desechar doctrinas erradas sobre dicha institución; y en segundo lugar, una crítica de los planteamientos en torno a la incapacidad de los hispanoamericanos de poner en práctica modelos judiciales y políticos.

Las obras de análisis en las que González basó su discurso sobre el jurado fueron: On the powers and duties of juries de S. R. Phillips, On civil liberty and self government de F. Lieber, A treatise on equity jurisprudence as administered in the United States of America de Jonh Pomeroy y Théorie du Jury on observations sur le Jury et sur les institutions judiciaires criminelles anciennes et modernes de Charles. F. Oudot ${ }^{56}$. En ellas afirmaba encontrar la doctrina que podía rectificar la lectura realizada por jurisconsultos como Joaquín Escriche, cuyas ideas habían sido las más difundidas en Hispanoamérica ${ }^{57}$. F. González remarcará una superioridad doctrinal de la literatura inglesa sobre la europea continental, por lo que no menciona el valor que le asignaron los primeros liberales de Colombia y muchos de sus contemporáneos

${ }^{54}$ Florentino González argumentó que en los Estados Unidos el poder judicial había llegado a desempeñar la función de un poder político, esta función consistía en su capacidad de poder interpretar las leyes, en poder establecer si eran o no constitucionales y por tanto legales, mediante lo que llegaba a tener el mismo nivel de jerarquía de los poderes ejecutivo y legislativo: "Esto resulta de la teoría misma del gobierno republicano; porque de otra manera los actos del Legislativo y el Ejecutivo vendrían en efecto á ser supremos é incontrolables, á pesar de cualesquiera prohibiciones y limitaciones contenidas en la constitución; y se cometerían usurpaciones del carácter más inequívoco y peligroso, sin remedio al alcance de los ciudadanos". GonZÁlez, 1869b, p. 423.

${ }^{55}$ Durante 1848-1850 F. González fue uno de los principales promotores del establecimiento del juicio por jurados para diversas causas criminales, y no sólo para delitos de libertad de imprenta. La ley sobre jurados fue sancionada en 1851 y la institución se mantuvo en vigor como mecanismo procesal con diferentes modificaciones hasta finales del siglo XX.

${ }^{56}$ Ver los datos bibliográficos de estas obras en el anexo.

${ }^{57}$ Dice González: "A Escriche no le ha ocurrido, ni podía ocurrirle a un español educado bajo el gobierno de los Borbones, considerar la institución como medio de dar al pueblo intervención en la administración de justicia y poder los derechos de los ciudadanos bajo la protección del mismo pueblo, de donde se sacan los hombres independientes que, llegada la ocasión, declaren si hay lugar á someter á un individuo á juicio, y después de sometido, resuelvan, si ha ejecutado un hecho criminal. Este abogado español no ha comprendido esto, porque en la escuela que se educó no podía aprenderlo". GonZÁlez, 1869a, pp. V y VI. 
a las ideas y a la literatura en materia de jurados que llegaron desde España. Habría que recordar que además de la legislación que llegó de España en la que se instituía el juicio por jurados como la ley de libertad de imprenta, también llegó literatura entre la que puede mencionarse obras como De las facultades y obligaciones de los Jurados, que era una traducción por Antonio Ortís de Zarate y Herrera de la obra de Sir Richard Phillips, y la obra De la prueba por jurados o sea consejo de hombres buenos $^{58}$ de Santiago Jonama.

A lo anterior se unía la refutación que hacía González del prejuicio respecto a la incapacidad de los pueblos hispanoamericanos para aplicar instituciones políticas que daban lugar a la participación popular como el juicio por jurado ${ }^{59}$. En primer lugar, respecto a la idea de que éste solo era viable para ciertas razas y sociedades civilizadas, afirmaba que se trataba de un sofisma utilizado por algunos sectores políticos que temían ver afectados sus intereses con la introducción de leyes y modelos extranjeros que promoverían instituciones libres. En contrapartida, González enfatizaba que las instituciones políticas eran una fuerza motora de la perfectibilidad social:

[...] hay, dice el americano Federico Grimke, una máxima antigua, que afirma que jamás puede hacerse que las instituciones políticas se pongan á un nivel más elevado que las costumbres; y jamás se ha incorporado ninguna más perniciosa en el libro de la política. Ninguna diferencia hay a este respecto entre las instituciones políticas y cualesquiera otras; y si tal máxima se hubiese puesto en práctica de algún modo que se pareciese a su plena extensión, la sociedad no habría dado un solo paso en la vía de las mejoras. Porque ¿qué son la religión, la educación y el cuerpo de reglas convencionales que presiden sobre una comunidad, sino otras tantas instituciones, que, al fundarse, hallaron á los hombres ignorantes y débiles, y los elevaron para hacerlos mejores y más sabios? La máxima verdadera es, que las instituciones políticas ejercen una importantísima influencia sobre las costumbres, y que toda mejora en ellas contribuye a elevar la sociedad á un nivel más alto ${ }^{60}$.

El ejemplo práctico que el jurista utilizó para mostrar que el juicio por jurados podía extenderse por Hispanoamérica sin temor al prejuicio de la incivilidad o de la corrupción racial, fue el caso de los Estados Unidos de Colombia, en donde el jurado, según argumentó, había acabado con la criminalidad y saneado la administración de justicia. Para esto González se sirvió básicamente de los juicios celebrados en Bogotá que se aplicaron a las bandas criminales que surgieron en 1850, juicios que coinci-

${ }^{58}$ La obra De las facultades y obligaciones de los jurados, fue impresa en Madrid en el año 1820, su editor y traductor, como era habitual en los escritores que apoyaban la revolución liberal, la dedicó a las Cortes extraordinarias del Reino. La obra De la prueba por jurados o sea consejo de hombres, fue igualmente impresa en Madrid en el año de 1820.

${ }_{59}$ La idea de incapacidad de los pueblos hispanoamericanos para practicar el juicio por jurados es abordada en obras como la de Thomas Flory. En Brasil las Cortes portuguesas prescribieron el juicio por jurados para delitos por libertad de imprenta al igual que las Cortes españolas y las discusiones que surgieron para ampliarlo a otros delitos criminales estuvieron marcadas por argumentaciones erradas que resaltaban la ignorancia de la población brasileña, las facilidad de corromper a los jurados a causa de su pobreza, la raza de los jurados, etc. Ver: FlorY, 1986, pp. 180-200.

${ }^{60}$ GonZÁlez, 1868a, pp. VIII-IX. 
dieron con la reforma de instituir el jurado para diferentes causas criminales, a la que apoyó como miembro del sector liberal colombiano en la década de $1850^{61}$.

Respecto a la oposición de los sectores dominantes a la utilización del juicio por jurados en Hispanoamérica, señaló que éstos estaban imbuidos de las máximas de los políticos de la Europa continental y dominados por la idea de la perfección de la jurisprudencia romana y napoleónica; razón por la que recurrían a los códigos de procedimiento franceses y españoles para arreglar modelos de enjuiciamiento propios. González opinaba que con ello se contribuía al establecimiento de un orden judicial contrario a las instituciones libres que subyacían en el modelo liberal republicano. El modelo adecuado para garantizar los derechos y las libertades y, por tanto, posibilitar un modelo representativo popular era el de la Gran Bretaña y los Estados Unidos; por esta razón González se acercó desde su juventud a obras de literatura jurídica de estos contextos como lo afirma en una de sus obras de referencia Elementos de Ciencia Administrativa publicada en 1840. En esta destaca precisamente algunas obras que contribuyeron a la transformación de su pensamiento sobre las instituciones colombianas.

[...] En medio del conflicto interior en que me encontraba, por la conviccion de que lo que había estudiado i enseñado no tendía á conseguir el objeto que se propone la lejislacion administrativa, llegó ahora tres años á este país la obra preciosa de Mr. Tocqueville: la lei, la medité; i ella fue para mi una antorcha que me condujo á un campo de investigaciones que me era desconocido. Poco tiempo después vino á mis manos el Digesto de Gordon i una noticia del sistema administrativo que se sigue en el imperio británico. Entonces, al cabo de dos años de incertidumbres i de errores, que no solo me afectaron á mi, sino también á mis discípulos, vinieron á fijarse mis ideas, llegué á percibir la senda por donde debía encaminar mi razón ${ }^{62}$.

\section{CONCLUSIONES}

En este artículo se han examinado diferentes aspectos relativos a la literatura jurídica de corte liberal-ilustrado que circuló en Colombia durante el siglo XIX. Como primera conclusión se aduce que la literatura jurídica que circuló en Colombia de forma predominante en la primera mitad del siglo XIX provino principalmente de la Europa continental. Estuvo conformaba por un conjunto amplio de obras en las que se expresaban doctrinas jurídicas como la del derecho natural moderno y en las que se realizaron diferentes análisis sobre las estructuras que debían adoptarse para el mejor funcionamiento del estado liberal republicano. A ellas se sumaban las de Jeremy Bentham, que si bien expresaban una doctrina que enfrentada a la del derecho natural, como fue la del utilitarismo, mantenía una

${ }^{61}$ El juicio principal referido por González parece ser el que se realizó a José Raimundo Russi y a la "banda" delincuencial el molino del cubo. Ver: Miramón, 1982, pp.133-244.

${ }^{62}$ González, 1840, pp. 1-2. 
misma línea en cuanto a analizar diferentes estructuras administrativas y jurídicas que hicieran más sólido un modelo pretendido.

De la circulación de esta literatura en el contexto colombiano habría que remarcar tres aspectos puntuales. Primero, fue concebida para remplazar buena parte de la literatura jurídica usada durante el periodo virreinal, lo que se logró si se considera la práctica que supuso el Plan de Estudios del 3 de octubre de 1826, observada a través de los certámenes públicos. Segundo, fue una literatura editada y traducida por autores españoles que en el caso de algunas obras alteraron la forma de los textos originales para asegurar su uso en el marco de la Monarquía hispánica; lo que tuvo repercusiones ideológicas directas en el contexto intelectual colombiano. Y, tercero, aunque esta literatura continúo circulando durante la segunda mitad del siglo XIX, su interés se redujo ante el despertado por el modelo estadounidense e inglés, como dio cuenta el análisis realizado a Florentino González.

Sobre el uso de la literatura jurídica presentada, los certámenes analizados han permitido observar los contenidos académicos estudiados, algunas de las ediciones consultadas y la forma en que fue extendiéndose su uso en las diferentes regiones del país en las que se abrieron cátedras de jurisprudencia. Un elemento que no se ha podido mostrar ha sido la cantidad de obras que llegaron a circular en el contexto colombiano. Un futuro estudio sobre las rutas comerciales del libro en el siglo XIX ayudaría a corroborar aspectos como la efectiva utilización de las obras como manuales tal como fue establecido por la ley.

Por último, sobre el alcance y las limitaciones que tuvo la política aperturista establecida por los gobernantes respecto a la literatura jurídica extranjera concretada en la reforma educativa de 1826, pueden destacarse los siguientes aspectos. Primero, los liberales colombianos encargados de realizar esta reforma no quisieron embarcarse en un proyecto de traducción y edición de obras jurídicas extranjeras, debido a la premura con que buscaban transformar la enseñanza jurídica en las facultades de jurisprudencia. Ello tuvo como consecuencia depender de las traducciones y ediciones publicadas casi en su totalidad en España. Segundo, no todas las obras que fueron establecidas dentro del programa de estudios y que figuraban como elementales fueron utilizadas en el contexto educativo colombiano, a causa de la dificultad para adquirir los textos o no estar traducida al castellano, siendo ejemplo de ello los trabajos de Joseph rey de Grenoble, y las obras de Bonnis y de Poiriez. Tercero, pudo observarse el interés que tuvieron los juristas colombianos por la literatura inglesa y norteamericana a partir de la segunda mitad del siglo XIX, esta fue comprendida como un panorama jurídico diferente al de la literatura europea continental atravesada por el ius commune, que podía dar lugar a la construcción de mejores modelos políticos. 


\section{REFERENCIAS BIBLIOGRÁFICAS}

ARIAS, Inmaculada

2005 "Libros extranjeros en bibliotecas privadas españolas del siglo XVIII". En Peralta, Víctor y otros (eds.). El equilibrio de los imperios: de Utrecht a Trafalgar. Actas de la VIII Reunión Científica de la Fundación Española de Historia Moderna. Madrid. Fundación Española de Historia Moderna. Vol. II, pp. 395-418.

Barbosa, Francisco Roberto

2007 Justicia: Rupturas y Continuidades el aparato judicial en el proceso de configuración del Estado-Nación en Colombia 1821-1853. Bogotá. Universidad Javeriana.

Bushnell, David

1984 El régimen de Santander en la Gran Colombia. 3ª Edición. Bogotá. El Áncora Editores.

CAMAcho, Salvador

1946 Memorias. Bogotá. Biblioteca popular de cultura colombiana.

CÉSPEDEs del CASTILLO, Guillermo

2007 "La independencia de las colonias inglesas y su proclamación en la América Virreinal". En Anes ÁlvVARez de CAstrillón, Gonzalo GARRIGUES, Eduardo. La ilustración española en la independencia de los Estados Unidos. Madrid. Marcial Pons, pp. 125-142.

Del Arenal, Jaime

1998 "Ciencia Jurídica Española en el México del siglo XIX”. En Jornadas de Historia del Derecho. México. Universidad Nacional Autónoma de México, pp. 31-48.

FLORY, Thomas

1986 El juez de paz y el jurado en el Brasil imperial. México. Fondo de Cultura Económica.

GaITÁn, Julio

2002 Huestes de Estado. La formación universitaria de los juristas en los comienzos del Estado colombiano. Bogotá. Universidad del Rosario.

GonZÁLEZ, Florentino

1840 Elementos de ciencia administrativa. Bogotá. Imprenta de J. A. Cualla.

1869a El juicio por jurados breve noticia. Del origen y progresos del jurado del modo de practicar la prueba judicial en Inglaterra y los Estados Unidos. Comparado con el otras naciones y razones a favor de esta institución. Buenos Aires. Imp. Lit fundición de tipos a Vapor.

1869b Lecciones de derecho constitucional. Buenos Aires. Universidad de Buenos Aires. Imp. Lit y función de tipos de J. A. Bernheim. 
HERnÁNDEZ, Guillermo

1985 Proceso contra don Antonio Nariño. Por la publicación clandestina de la Declaración de los derechos del Hombre y del Ciudadano. Bogotá. Colección presidencia de la República.

LÓPEZ, Luís Horacio (Comp.)

1990 Administraciones de Santander 1820-1825. Tomo I. Bogotá. Biblioteca de la presidencia de la República.

LóPEz Domínguez, Luís Horacio (coord.)

1993 Santander y Los libros. Tomo II. Bogotá. Presidencia de la República.

Luque, Miguel y Vas Mingo, Marta del

2006 "El comercio librario: mecanismos de distribución y control de la cultura escrita en Indias". Revista Complutense de Historia de América. Madrid. $\mathrm{n}^{\mathrm{o}} 32$, pp. 127-149.

MÁrquez, Rosario

2002 El trasvase cultural a América, las bibliotecas privadas de los emigrantes españoles en el siglo XVIII. Sevilla. Aconcagua Libros.

Martínez NeIRA, Manuel

1998 "Lecturas antiguas y lecturas ilustradas: una aproximación a los primeros manuales jurídicos". Cuadernos del Instituto Antonio de Nebrija. Madrid. $n^{\circ}$ 1, pp. 143-209.

Martínez Briceño, Rafael

1993 "La biblioteca del General Santander". En López Domínguez, Luís Horacio (coord.). Santander y los libros. Tomo II. Bogotá. Presidencia de la República, pp. 59-72.

MirAMÓN. Alberto

1982 Tres personajes históricos, Arganil, Russi y Oyón. Bogotá. Academia Colombiana de Historia. Editorial Plaza y Janes.

Molano, Enrique

1999 Antonio Nariño. Filósofo Revolucionario. Bogotá. Planeta.

Moreno DE ÁNGel, Pilar

1989 Santander. Bogotá. Planeta.

PeÑAs, Aura

2006 Génesis del sistema penal colombiano. Utilitarismo y tradicionalismo en el código penal neogranadino de 1837. Bogotá. Ediciones doctrina y ley.

RIBOT Y MARCH, Genaro

1924-1954 Codificación nacional de todas las leyes de Colombia desde el año de 1821, hecha conforme a la ley 13 de 1912. Bogotá. Imprenta Nacional. 
Ruíz, Eduardo

1990 La librería de Nariño y los derechos del hombre. Bogotá. Planeta. 1993a "Santander y los libros". En López Domínguez (coord.), pp. 75-105.

1993b "Catalogo de libros de la biblioteca de Santander". En LóPEZ DomíngueZ, (coord.), pp. 107-273.

SiLva, Renán

2002 Los ilustrados de Nueva Granada 1760-1808. Medellín. Banco de la República. EAFIT.

SALA, Juan

1803 Ilustración del derecho real de España. Valencia. Imprenta de José de Orga.

TORRES, José María

1868 Ensayos biográficos y de crítica literaria sobre los principales publicistas, historiadores, poetas y literatos de la América Latina. París. Baudry. Librería europea. 


\section{FUENTES}

Gaceta de Colombia, publicación oficial del Estado de la Gran Colombia, números: $120,132,147,175,197,215,308,322$.

Gaceta de la Nueva Granada, publicación oficial del Estado de la Nueva Granada, números: 106, 166, 176, 212, 221, 329, 330, 378, 379, 390.

Proyecto de Código Penal para Colombia tomado con las variaciones necesarias del que presentó a las Cortes españolas por una Comisión en el año de 1821. Bogotá. Imprenta de la República de Colombia. 1823.

Código penal sancionado por el Congreso de la Republica en 1837. Bogotá. Imprenta Nicomedes Lora. 1837.

Espinosa, Bruno (compilador e impresor del gobierno). Cuerpo de Leyes de la República de Colombia, comprende la Constitución y las leyes sancionadas por el primer Congreso general en las sesiones que celebró desde el 6 de mayo hasta el 14 de octubre de 1821. Bogotá. Imprenta de Bruno Espinosa. 1822.

GonzÁlez, Ramón. Leyes y decretos expedidos por el Congreso Constitucional de la Nueva Granada en el año de 1848. Bogotá. Imprenta El Neogranadino. 1850.

\section{ANEXO}

\section{Obras prescritas para las cátedras en el plan de estudios de jurisprudencia de 1826}

\begin{tabular}{|c|c|c|}
\hline Cátedras & $\begin{array}{l}\text { Obras-manuales, indispensables } \\
\text { para la cátedra }\end{array}$ & Secundarias (para el apoyo docente) \\
\hline $\begin{array}{l}\text { Cátedra de Principios } \\
\text { de legislación univer- } \\
\text { sal y de legislación } \\
\text { civil y penal. }\end{array}$ & $\begin{array}{l}\text { Bentham, Jeremy. Tratados de } \\
\text { legislación civil y penal. Madrid. } \\
\text { Fermín Villalpando, 1820, } 5 \mathrm{~V} \text {; Pa- } \\
\text { rís (editor René Masson), 1823, } 8 \\
\text { V.; Burdeos, } 1829,8 \mathrm{~V} \text {. Todas las } \\
\text { traducciones de esta obra fueron } \\
\text { hechas por Ramón de Salas. } \\
\text { Grenoble, Joseph Rey. Des ins- } \\
\text { titutions judiciaires de l'Angleterre } \\
\text { comparées avec celles de la Fran- } \\
\text { ce, et de quelques autres états, en- } \\
\text { ciens et modernes. París. } 1826 \text {. } \\
\text { Grenoble, Joseph Rey. Traité } \\
\text { des principles Généraux du droit } \\
\text { et de la législation. París. Alex- } \\
\text { Gobelet. 1828. } \\
\text { Grenoble, Joseph Rey. Adresse } \\
\text { a L'Empereur. París. Eymery. Li- } \\
\text { braire. } 1815 \text {. }\end{array}$ & $\begin{array}{l}\text { Para esta cátedra se planteó que } \\
\text { el profesor debía consultar los prin- } \\
\text { cipios de legislación universal por } \\
\text { un anónimo, al igual que podía apo- } \\
\text { yarse en las obras "clásicas" para } \\
\text { explicar cuestiones de ciencia de la } \\
\text { legislación. } \\
\text { En apoyo de esta cátedra los pro- } \\
\text { fesores pudieron haber utilizado las } \\
\text { obras del español Marcos Gutiérrez } \\
\text { sobre la que algunos juristas colom- } \\
\text { bianos de la época enfatizaron su } \\
\text { circulación en las librerías. } \\
\text { Marcos Gutiérrez, Joseph. Prác- } \\
\text { tica criminal de España. Madrid. } \\
\text { Oficina de don Benito García y } \\
\text { Compañía. } 2 \text { tomos. } 1804 \text {. Esta obra } \\
\text { tiene varias ediciones posteriores. }\end{array}$ \\
\hline
\end{tabular}


Cátedra de derecho público político, constitución y ciencia administrativa
Constant, Benjamin, Collection complete des ouvrages publiés sur le Gouvernement representatif et la constitution actuelle de la France Jonnant un especie de Cours de politique constitutionnelle. París. Plancher. 4 Vol. (18181819).

Las obras utilizadas en el contexto colombiano fueron las ediciones castellanas de Marcial Antonio López:

Constant, Benjamín, Curso de política constitucional. Madrid. Imprenta de la Compañía. 3 Vol. 1820. Tiene otras ediciones posteriores, una publicada en Gerona en 1823 y otra en Burdeos en el mismo año.

Charles-Jean, Bonnin, Doctrina social o principios universales de las leyes y sus relaciones de pueblo a pueblo deducidas de los derechos del hombre y de los del género humano. Esta fue enviada por su autor a Simón Bolívar en el año de 1822. Se desconocen sus datos editoriales.

Obras realizadas por juristas colombianos:

González, Florentino. Elementos de ciencia administrativa. Comprende el bosquejo de un sistema de administración pública para un estado republicano. Bogotá. Imprenta de J. A Cualla. 1840. 2 Vol.

Pinzón Cerbeleón. Principios sobre administración pública. Bogotá, Imprenta de J. A. Cualla. 1847.

Pinzón, Cerbeleón. Tratado de Ciencia Constitucional. Bogotá. Imprenta de Nicolás Gómez. 1839. 2 Vol.

Del Real, Antonio, Elementos de derecho constitucional seguidos de un examen crítico de la constitución neogranadina. Cartagena. Imprenta de Eduardo Hernández. 1839.
Mably, Abbé. Le droit public de l'Europe, fondé sur les traites. Esta obra fue publicada por primera vez en 1740 , y fue ampliamente reeditada durante el siglo XVIII.

$\mathrm{Su}$ primera traducción en castellano la hizo en 1746 Joseph Antonio de Abreu y Bertodano, y fue publicada en Madrid en la Oficina de la viuda de Diego Peralta, con el titulo Derecho público de la Europa: fundado en los tratados concluidos hasta el año de 1740.

Montesquieu, Barón de Secondat. El espiritu de las leyes. Madrid, Imprenta de Villalpando. 1820. De esta obra, cuya primera edición en francés data de 1748 , se realizaron varias ediciones en castellano desde finales del siglo XVIII. En el Virreinato de la Nueva Granada circularon algunas ediciones en francés y en castellano.

Fritot, Alb. Cours de droit natural, public, politique et constitucionel. París. Aillaud, Libraire. 1827. 


\begin{tabular}{|c|c|c|}
\hline $\begin{array}{l}\text { Cátedra de historia } \\
\text { e instituciones de } \\
\text { derecho civil, romano } \\
\text { y derecho patrio }\end{array}$ & $\begin{array}{l}\text { Heinecio, Elementos del } \\
\text { Derecho Romano. Madrid, } \\
\text { Imprenta de D. Eusebio Aguado, } \\
\text { 1829. Traducidos y anotados por J. } \\
\text { A. S, con Licencia. Esta obra tuvo } \\
\text { ediciones anteriores y posteriores. } \\
\text { Sala, Juan. Ilustración del } \\
\text { derecho real de España. Valencia, } \\
\text { Imprenta de Joseph de Orga. 1803. } \\
\text { Publicada con permiso. Existieron } \\
\text { varias ediciones. Antonio } \\
\text { Prieto Sotelo, Anto derecho } \\
\text { Fernández. Historia del dera } \\
\text { real de España. Madrid. 1738. } \\
\text { Tuvo otras ediciones posteriores. }\end{array}$ & $\begin{array}{l}\text { En un decreto establecido el } 26 \text { de } \\
\text { octubre de } 1836 \text { se prescribió el uso } \\
\text { de la obra Instituciones del derecho } \\
\text { real de España de José María } \\
\text { Álvarez. De esta obra conocemos la } \\
\text { publicada en la imprenta de Repullés } \\
\text { en el año de } 1829 \text { en } 2 \text { Vol. }\end{array}$ \\
\hline $\begin{array}{l}\text { Cátedra de economía } \\
\text { politica. }\end{array}$ & $\begin{array}{l}\text { Say, Juan Bautista. Tratado de } \\
\text { economía politica o exposición } \\
\text { sencilla del modo con que se } \\
\text { forman, se distribuyen y se } \\
\text { consumen las riquezas. Madrid. } \\
\text { 1804-1808. } 3 \text { Vol. La obra tuvo } \\
\text { diversas ediciones posteriores en } \\
\text { castellano. }\end{array}$ & \\
\hline $\begin{array}{l}\text { Catedra de derecho } \\
\text { internacional o de } \\
\text { gentes. }\end{array}$ & $\begin{array}{l}\text { Vattel, Emer. El derecho de } \\
\text { gentes, o principios de la ley } \\
\text { natural aplicados a la conducta } \\
\text { y a los negocios de las naciones } \\
\text { y de los soberanos. Madrid. } \\
\text { Sancha. } 4 \text { Vol. 1820. La obra tuvo } \\
\text { diversas ediciones posteriores en } \\
\text { castellano: 1822, 1824, } 1834 \text {. } \\
\text { Obras de juristas en el contexto } \\
\text { de la Gran Colombia. } \\
\text { Yanes, Francisco Javier. Idea } \\
\text { general ó principios elementales } \\
\text { del derecho de gentes: extracto } \\
\text { de Vattel y otros autores. Caracas. } \\
\text { Imprenta de Tomás Antero. } 1824 . \\
\text { Bello, Andrés. Principios de } \\
\text { derecho de gentes. Santiago de } \\
\text { Chile. Imprenta de la opinión. } \\
\text { 1832. }\end{array}$ & $\begin{array}{l}\text { Martens, Karl. Manual } \\
\text { diplomático, ó compendio de } \\
\text { los derechos y funciones de los } \\
\text { agentes diplomáticos. Seguido de } \\
\text { una colección de actas y oficios } \\
\text { escogidos para servir de modelo } \\
\text { a las personas que se dedican á la } \\
\text { carrera diplomática. París, Librería } \\
\text { Americana, 1826, } 3 \text { Volúmenes, } \\
\text { traducido al castellano por Mariano } \\
\text { José Sicilia. } \\
\text { Burlamaqui, Juan Jacobo, } \\
\text { Elementos de derecho natural. } \\
\text { Madrid. } 1820 \text {. Obra que tuvo varias } \\
\text { ediciones posteriores en castellano. } \\
\text { Azuni, Domingo Alberto. } \\
\text { Sistema universal de los principios } \\
\text { del derecho maritimo de la } \\
\text { Europa. Madrid. Imprenta Gómez } \\
\text { Fuentenebro y Compañía } 1803 \text {. }\end{array}$ \\
\hline
\end{tabular}




\section{Obras sobre la influencia inglesa y norteamericana.}

Obras escritas por Florentino González en Argentina y obras destacadas por éste respecto al tema del jurado:

-González, Florentino. El juicio por jurados, breve noticia. Del origen y progresos del jurado del modo de practicar la prueba judicial en Inglaterra y los Estados Unidos. Comparado con el de otras naciones y razones a favor de esta institución. Buenos Aires. Imp., Lit y fundición de tipos a Vapor. 1869.

-González, Florentino. Lecciones de derecho constitucional. Universidad de Buenos Aires. Imp. Lit y función de tipos de J. A. Bernheim. 1869.

-Phillips, Sir Richard. On the Powers and Duties of Juries. London, Sherwood and Co, London, 1811.

-Lieber, Francis. On Civil Liberty and Self Government. London. Richard Bentley. 1835.

-Oudot François. Théorie du Jury ou observations sur le Jury et sur les institutions judiciaires criminelles anciennes et moderns. Paris. Joubert, Libraire de la Cour de cassation. 1843.

-Tocqueville, Alexis. De la democracia en la América del Norte. París. Rosa, 22, calle Hauteville. 1837.

-Torres Caicedo, José María. Estudios sobre el gobierno inglés y sobre la influencia anglosajona. París. Baudry, Librería Europea. 1868.

Obras sobre el jury escritas o traducidas en el contexto de las Cortes liberales del Trienio.

-Phillips, Richard, De las facultades y obligaciones de los jurados, Madrid. Imprenta de Sancha. 1821. La obra fue editada por Antonio Ortiz de Zarate y Herrera, quien la aumentó con una parte legislativa sobre la práctica de jurados en Francia y en los Estados Unidos.

-Jonama, Santiago. De la prueba por jurados o sea consejo de hombres buenos. Madrid. Imprenta Censor. 1820. 